\title{
STUDIES OF LOW TEMPERATURE PHASE TRANSFORMATIONS IN \\ HIGH FIELD SUPERCONDUCTORS AND THE PHONON SPECTRUM \\ AND MECHANICAL PROPERTIES OF VANADIUM
}

Final Report

\author{
B. W. Batterman \\ Department of Materials Science and Engineering \\ Corne11 University \\ I thaca, New York 14850
}

PREPARED FOR THE U. S. ATOMIC ENERGY COMMISSION CONTRACT \# AT $(11-1)-3164$

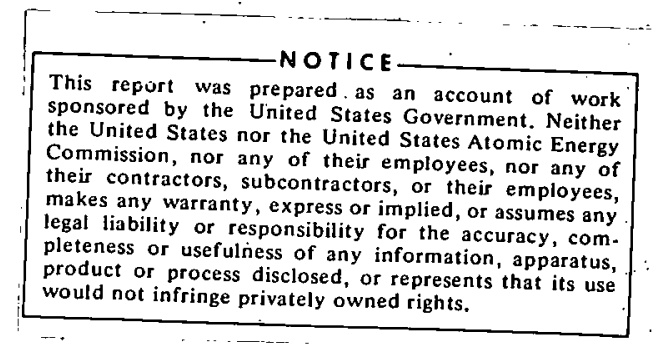

\section{MASTER}

DISTRIBUTION OF THIS DOCUMENT IS UNLIMITED 


\section{DISCLAIMER}

This report was prepared as an account of work sponsored by an agency of the United States Government. Neither the United States Government nor any agency Thereof, nor any of their employees, makes any warranty, express or implied, or assumes any legal liability or responsibility for the accuracy, completeness, or usefulness of any information, apparatus, product, or process disclosed, or represents that its use would not infringe privately owned rights. Reference herein to any specific commercial product, process, or service by trade name, trademark, manufacturer, or otherwise does not necessarily constitute or imply its endorsement, recommendation, or favoring by the United States Government or any agency thereof. The views and opinions of authors expressed herein do not necessarily state or reflect those of the United States Government or any agency thereof. 


\section{DISCLAIMER}

Portions of this document may be illegible in electronic image products. Images are produced from the best available original document. 


\section{ABSTRACT}

In the research on this contract we have made extensive studies of the structure and phase transformations of high field superconductors of the $\beta$-tungsten type. We discovered a phase transformation at $43^{\circ} \mathrm{K}$ in $\mathrm{Nb}_{3} \mathrm{Sn}$ and have measured the structure of the low temperature phase. The details of the transformation in terms of the formation of the low temperature tetragonal phase from the high temperature cubic phase was investigated both by $x$-ray observations and optical microscopy below $40^{\circ} \mathrm{K}$.

The complete phonon dispersion of vanadium was measured by $x$-ray diffuse scattering, thus complementing the neutron measurements on other body-centered cubic elements. Incidental to the work on phonons in vanadium we discovered a strong effect which we were able to relate to hydrogen precipitations in vanadium. In separate electron microscopy studies we determined the structure of the vanadium hydride phase directly and determined the relative positions of the hydrogen atoms. In a neutron diffraction study complementing our phonon work with $x$-rays we were able to show directly the existence of anharmonic vibrations in single crystals of silicon by determining, for the first time, a nuclear forbidden reflection. This reflection is due solely to anharmonic vibration of the nucleus of the atom and we were able to show that its intensity increases with increasing temperature roughly as the 4 th power of temperature. 
This final report describes the work performed under contract number AT(11-1)-3164 entitled "Studies of Low

Temperature Phase Transformations in High Field Superconductors and the Phonon Spectrum and Mechanical Properties of Vanadium".

The initial phase of this work was concerned with the compounds $\mathrm{Nb}_{3} \mathrm{Sn}$ and $\mathrm{V}_{3} \mathrm{Si}$ which are high temperature superconductors. When this work was initiated it had been established previously in the literature that $\mathrm{V}_{3} \mathrm{Si}$ underwent a structural phase transformation at a temperature of about $23^{\circ} \mathrm{K}$ compared to a superconducting transition temperature of $17.3^{\circ} \mathrm{K}$. Attempts to show that $\mathrm{Nb}_{3} \mathrm{Sn}$ whose superconducting transition temperature is $18.5^{\circ}$ and also has the same transition as $V_{3} S i$ had failed. When we started this work we were able to obtain from J. J. Hanak of the RCA Laboratories a single crystal of $\mathrm{Nb}_{3} \mathrm{Sn}$ and were able to show after appropriate heat treatment of that crystal that $\mathrm{Nb}_{3} \mathrm{Sn}$ also underwent a phase transformation in a way similar to $\mathrm{V}_{3} \mathrm{Si}$ with interesting differences. The transition temperature of the structural transformation was $43^{\circ} \mathrm{K}$ and that the change from cubic to tetragonal in $\mathrm{Nb}_{3} \mathrm{Sn}$ was such that the $c$ axis became smaller than the two a's whereas the reverse was the case in $\mathrm{V}_{3} \mathrm{Si}$. We then undertook a detailed study using optical techniques at helium temperatures to get information on the mechanism of the low temperature transformations. We were able to do optical microscopy at helium temperatures and to record the progress of the transformation using cine techniques. We could see the formation of the 
tetragonal structure and its propagation and stress dependence while the transformation took place.

Detailed $x$-ray measurements on both $\mathrm{V}_{3} \mathrm{Si}$ and $\mathrm{Nb}_{3} \mathrm{Sn}$ were made to establish that there was no volume change to one part in $10^{4}$ in the transformation from cubic to tetragonal. A11 our results indicated that the transformation was at least second order as far as the strain parameters were concerned.

It was known that acoustic modes became soft in both these materials as the transformation temperature was approached. We attempted to measure an expected increase in the thermal $x$-ray scattering as the transformation temperature was approached.

To develop our techniques for the measurement of thermal diffuse scattering we measured the thermal scattering from single crystals of vanadium to get the phonon dispersion curves. Vanadium is a material which is unsuitable for neutron diffraction determinations of the phonon spectrum because of its low coherent scattering cross-section. We made the first $x$-ray measurements on single crystals of vanadium to get the phonon dispersion curves. This work was published in 1970 . During these $x$-ray measurements of thermal scattering we incidentally discovered peculiar effects of hydrogen in the vanadium samples and this led to a study of the effects of hydrogen in vanadium. In collaboration with Professor S. L. Sass and graduate student John Wanagel we made a detailed study of the formation of vanadium hydride precipitating in a vanadium matrix. Electron microscopy studies showed the ordering of hydrogen atoms in the vanadium hydride and we were 
able to get a structure, for the first time, of the tetragonal vanadium hydride phase. We were also able to obtain the relative positions of hydrogen atoms in the hydride and thus determined the superstructure of the hydrogen atoms.

Incidental to our study of phonon properties in solids we were interested in anharmonic vibrations which we would expect to take place in solids in which soft phonons appear. One unique method of directly seeing anharmonic vibrations is to look at the neutron diffraction intensities of certain forbidden reflections, e.g., the (222). This reflection would normally be forbidden, but if the nucleus vibrates in an anharmonic way, the symmetry of the lattice, would allow a weak (222) reflection. Furthermore, contrary to the usual dependence of Bragg reflections on temperature these reflections increase with temperature roughly as the power of $\mathrm{T}^{4}$. The reason for the increase is that the degree of anharmonicity will increase as the vibrational amplitude of the nucleus increases with increasing temperature. We were able to detect and measure this anharmonic reflection. 


\section{PUBLICATIONS}

1. "Low Temperature Structural Transformation in $\mathrm{Nb}_{3} \mathrm{Sn}$, (with R. Mailfert, J. Hanak), Phys. Lett. 24, 315, (1967).

2. "Search for Sublattice Distortion in $\mathrm{V}_{3} \mathrm{Si}$ ", (with $\mathrm{J}$. Pere1 and E. I. Blount), Phys. Rev. 166, 616, (1968).

3. "Observations Related to the Order of the Low Temperature Phase Transformation in $\mathrm{V}_{3} \mathrm{Si}$ and $\mathrm{Nb}_{3} \mathrm{Sn}^{\prime}$, (with R. Mailfert and J. Hanak), Physica Stat. So1. 32, (1969).

4. "X-Ray Determination of Phonon Dispersion in Vanadium", (with R. Cole1la), Phys. Rev. B 1, 3913, (1970).

5. "Crystallographic Study of the Low Temperature Phase Transformation in $\mathrm{V}_{3} \mathrm{Si}$ and $\mathrm{Nb}_{3} \mathrm{Sn}$ (with $\mathrm{J}$. Wanage 1 ), J. App 1. Phys. 41, 3610, (1970).

6. "Anharmonicity and the Temperature Dependence of the Forbidden (222) Reflection in Silicon", Phys. Rev. Lett. 27, 320 , (1971).

7. "The Ordering of Hydrogen in B-Vanadium Hydride", (with J. Wanage 1 and S. L. Sass), Phys. Stat. Solidi (a), 10, 49, (1972).

8. "The Forbidden (222) Neutron Reflection in Silicon, Anharmonicity and the Bonding Electrons", (with D. Keating, A. Nunes and J. Hastings), Phys. Rev. B, 2472, (1971).

9. "Low Temperature Phase Transformation in the VanadiumHydrogen System", (with J. Wanagel and S. L. Sass), Phys. Stat. Solidi (a) (1972).

10. "The Ordering of Hydrogen in B-Tantalum Hydride", (with J. Wanage 1 and S. L. Sass), Phys. Stat Solidi (a), k97, (1972).

11. "Observations on the Microstructure and Orientation Relations in the Vanadium-Hydrogen System", (with J. Wanage 1 and S. L. Sass), accepted for publication in Met. Transactions. 